\title{
AS METAMORFOSES SOCIOESPACIAIS RESULTANTES DO INCREMENTO DA PRODUÇÃO DE LEITE: UMA ANÁLISE DESTA ATIVIDADE NO MUNICÍPIO DE ITUIUTABA/MG NO PERÍODO DE 1960 A 2013
}

\section{The sociospatial metamorphosis resulting from milk production increment: an analysis of this activity in the city of Ituiutaba/MG during the period of 1960 to 2013}

Thales Silveira Souto Universidade Federal de Santa Maria, Santa Maria, Rio Grande do Sul, Brasil. thales.souto@hotmail.com

Meri Lourdes Bezzi Universidade Federal de Santa Maria, Santa Maria, Rio Grande do Sul, Brasil. meribezzi@yahoo.com.br

Artigo recebido em 22/09/2015 e aceito para publicação em 06/07/2016

RESUMO: A pecuária leiteira obteve considerável crescimento em Ituiutaba/MG a partir da implantação de uma unidade multinacional processadora de leite no ano de 1974, como também, devido a existência da demanda de outras agroindústrias leiteiras, aumentando a produção de leite em 325.3\% no período de 1975 a 2013 (IBGE, 2013). Nesta perspectiva, objetivou-se analisar as transformações socioespaciais resultantes da expansão da produção leiteira em Ituiutaba, no período de 1960 a 2013. Especificamente, buscou-se (a) compreender os entraves referentes ao desenvolvimento deste setor no cenário agropecuário brasileiro; (b) verificar a importância da implantação das unidades industriais processadoras de leite em Ituiutaba para a manutenção e/ou crescimento deste setor produtivo; (c) conhecer a realidade vivenciada pelo produtor leiteiro em Ituiutaba. Metodologicamente, a pesquisa foi desenvolvida em etapas. Na primeira etapa, fez-se o levantamento bibliográfico. Posteriormente, coletou-se dados secundários da produção agropecuária de Ituiutaba na escala temporal de 1960 a 2013, por meio dos Censos Agrícola de 1960 e Agropecuários de 1970, 1980, 1996 e 2006 do Instituto Brasileiro de Geografia e Estatística - IBGE e em demais bancos de dados disponíveis no site do IBGE. A terceira fase relacionou-se ao desenvolvimento do trabalho de campo. Nesta houve a realização de entrevistas com os sujeitos da pesquisa. Na última etapa, analisou-se e interpretou-se as informações coletadas, resultando a compreensão das transformações procedidas do incremento produtivo leiteiro em Ituiutaba.

Palavras-chave: Expansão; Pecuária leiteira; Transformações; Ituiutaba/MG.

ABSTRACT: The dairy industry has obtained considerable growth in Ituiutaba/MG from the implementation of a milk processor multinational unit in 1974, as also due to the existence of demand for other dairy agribusiness, increasing milk production to $325.3 \%$ from 1975 to 2013 (IBGE, 2013). In this perspective, the aim was to analyze the socio-spatial transformations resulting from the expansion of milk production in Ituiutaba, from 1960 to 2013. Specifically, we sought to (a) understand the barriers for the development of this sector in the Brazilian agricultural scene; (b) verify the importance of the development of industrial milk processing units in Ituiutaba for maintenance and/or growth of the productive sector; and (c) know the reality experienced by the dairy producer in Ituiutaba. Methodologically, the research was developed in 
As metamorfoses socioespaciais resultantes do incremento da produção de leite: uma análise desta atividade no município de Ituiutaba/MG no período de 1960 a 2013

Thales Silveira Souto, Meri Lourdes Bezzi

steps. In the first step was done the bibliographic research Subsequently it was collected secondary data from Ituiutaba's agricultural production within the timeline from 1960 to 2013, using the Agricultural sense of 1960 and the agriculture and husbandry sense of 1970, 1980, 1996 and 2006 from the Brazilian Institute of Geography and Statistics - IBGE and other databases available in the IBGE website. The third phase is related to the development of field work. It was conducting interviews with the subjects. In the last step, we analyzed and interpreted the information collected, resulting in an understanding of the transformations proceeded from the increment of dairy production in Ituiutaba.

Keywords: Expansion; Dairy farming; Transformations; Ituiutaba/MG.

\section{INTRODUÇÃO}

A produção de leite é uma atividade que é realizada com maior ênfase principalmente nas unidades federativas de Minas Gerais, Rio Grande do Sul e Paraná, os quais, juntos, representam 52,4\% da produção nacional no ano de 2013. Contudo, vale salientar que o estado de Minas Gerais corresponde ao total de 27,2\% da produção brasileira (IBGE, 2013).
Destaca-se a importância desta atividade para o alicerce econômico e, também, no processo organizacional socioespacial mineiro.

Neste cenário, salienta-se o município de Ituiutaba/MG, no qual ocorreu o crescimento da produção de leite, especialmente, após a instalação de uma unidade transformadora de leite em pó, a Nestlé, no ano de 1974 e, que iniciou a coleta do leite em 1976 (Figura 01).

Figura 01 - Localização do município de Ituiutaba/MG na Microrregião Geográfica de Ituiutaba (MRG 017)
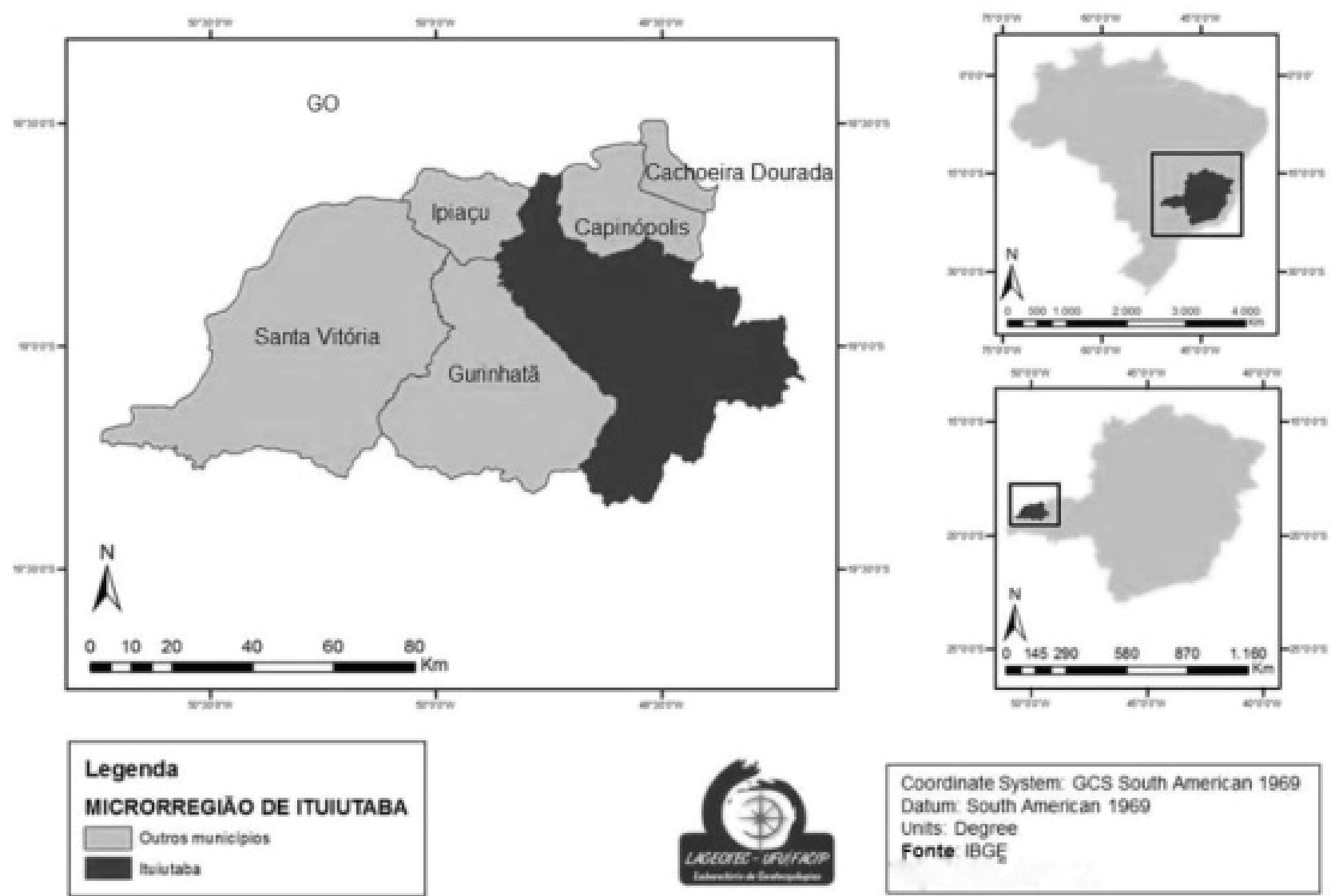

Fonte: Base Digital do Instituto Brasileiro de Geografia e Estatística - IBGE, 2010. 
Ressalta-se que, entre os anos de 1960 a 1975 , em Ituiutaba houve um crescimento da produção leiteira de $110,5 \%$. Entretanto, após a implantação da Nestlé, verificou-se no período de 1975 a 2013 um crescimento de $325,3 \%$ da produção de leite (IBGE, 2013) devido a expansão da demanda por esta matéria prima. Embora as demais atividades, como relacionada a pecuária de corte bovino, suína e de aves, além do setor agrícola, tendo grandes produções, entre elas a cana de açúcar e a soja, aponta-se que a pecuária leiteira tem valor fundamental na dinâmica produtiva agropecuária na escala temporal analisada.

Neste sentido, a problemática desta investigação consistiu em verificar a atuação do setor produtivo leiteiro deste município, frente às principais atividades agropecuárias, analisando se houve a evolução e/ou a estagnação desta produção, bem como, constatar a importância desta cadeia produtiva na organização/ reorganização espacial local.

Portanto, justifica-se que a realização desta pesquisa vem de encontro com a necessidade de compreensão das transformações resultantes da expansão produtiva leiteira nesta unidade territorial, resultando o entendimento da atuação desta atividade frente as demais produções agropecuárias neste recorte temporal estabelecido.

O objetivo central foi analisar as transformações resultantes da expansão da produção de leite em Ituiutaba, no período de 1960 a 2013. Em relação aos objetivos específicos, buscou-se: (a) compreender os entraves referentes ao desenvolvimento deste setor no cenário agropecuário brasileiro; (b) verificar a importância da implantação das unidades industriais processadoras de leite no município de Ituiutaba para a manutenção e/ou crescimento deste setor produtivo; e (c) conhecer a realidade vivenciada pelo produtor leiteiro de Ituiutaba.

O presente trabalho trilhou caminhos fundamentais para a sua organização. Para tanto, delineou-se os procedimentos metodológicos seguindo a dinâmica vinculada à necessidade da compreensão dos principais aspectos balizadores e transformadores locais. Neste, selecionou-se a abordagem da pesquisa qualitativa, auxiliando a verificação, análise e diagnóstico referente à temática abordada. No que tange a estrutura organizacional metodológica desta inves- tigação, ressalta-se a primeira etapa, a qual foi alicerçada ao levantamento bibliográfico, proporcionando o entendimento dos principais conceitos norteadores para a compreensão da organização/reorganização socioespacial brasileira por meio do incremento da agricultura, bem como, os entraves e as perspectivas da cadeia produtiva do leite, fazendo um link à realidade vivenciada em Ituiutaba. Na segunda etapa, realizou-se a coleta de dados em fontes secundárias, na escala temporal de 1960 a 2013 por meio dos Censos Agrícolas de 1960 e Agropecuários de 1970, 1980, 1996 e 2006 do IBGE e, também, através das demais informações disponíveis nos bancos de dados do IBGE, como por meio da Pesquisa Pecuária Municipal, a qual possui dados anuais do período de 1974 a 2013 e, Produção Agrícola Municipal, contemplando dados anuais de 1990 a 2013. Na terceira etapa, fez-se o trabalho de campo. Neste momento, realizaram-se entrevistas estruturadas em questionários aos sujeitos da investigação. Inicialmente, entrevistou-se 64 produtores de leite, os quais foram selecionados com o auxílio de um extensionista aposentado da EMATER. Salienta-se que, realizou-se a amostragem por acessibilidade ou por conveniência, essa é ressaltada por Gil (2008, p. 94) como o tipo de amostragem com menor nível de rigorosidade, não considerando o rigor estatístico. Posteriormente, realizou-se entrevistas às agroindústrias transformadoras de leite ( 3 fábricas instaladas em Ituiutaba), as instituições agropecuárias (4 instituições) e as empresas do ramo agropecuário desta unidade territorial (6 empresas). Após, gerou a produção de gráficos e tabelas para exposição das informações coletadas em campo e dos dados secundários. Como resultado, realizou-se a análise da importância da produção de leite na dinâmica produtiva, espacial e econômica na unidade territorial investigada.

Neste contexto, foi possível verificar as transformações procedidas do incremento produtivo leiteiro em Ituiutaba, na escala temporal correspondente, conhecendo a atuação deste setor frente às demais atividades produtivas neste município. 
As metamorfoses socioespaciais resultantes do incremento da produção de leite: uma análise desta atividade no município de Ituiutaba/MG no período de 1960 a 2013

Thales Silveira Souto, Meri Lourdes Bezzi

\section{O INCREMENTO DA PECUÁRIA LEITEIRA NO CENÁRIO AGROPECUÁRIO BRASILEIRO}

A pecuária leiteira teve sua gênese no principio da colonização do território brasileiro, sendo que a criação de gado de acordo com Valverde (1967) foi uma importante atividade econômica no período do Brasil-Colônia. Inicialmente, o gado era criado com mínimos aparatos técnicos, viviam à solta, sem silagem ou melhoria dos pastos, faziam apenas queimadas periódicas do capim.

Por meio do processo de independência e desenvolvimento político, aliado a necessidade de atividades produtivas alicerçadas ao uso do solo rural para a evolução econômica, priorizou-se, a ampliação das atividades ligadas ao campo, as quais, até então, eram desenvolvidas pelos modos tradicionais. Utilizavam-se os aparatos técnicos pertinentes ao período (MAZOYER; ROUDART, 2010).

Neste contexto, aponta-se que a agricultura brasileira não se desenvolveu de forma sistêmica, ou seja, houve a expansão de algumas atividades, principalmente as que tangem a necessidade do mercado externo, deixando a margem os setores de menor interesse.

Considera-se que, neste cenário, a agricultura, que até a metade do século XX era desenvolvida em grande parte do território nacional de forma tradicional, a partir do desenvolvimento de políticas públicas, juntamente com o interesse do capital internacional, priorizaram a inserção de técnicas e tecnologias, aliado à realização de estudos para maior e melhor produtividade. No entanto, ao considerar a pecuária leiteira, Vilela; Bressan; Cunha (2001, p. 9) ressaltam que,

Em meio a essas histórias de sucesso, o leite mal cobriu o fundo do copo. Qualquer que seja o indice de eficiência que se olhe, o setor de lácteos aparece à frente de uma lista de exceções no processo de modernização das atividades agroindustriais. Desta lista fazem parte alguns produtos típicos de consumo doméstico, como feijão, mandioca, batata-doce, entre outros, e mesmo o conjunto das atividades de algumas áreas menos desenvolvidas, notadamente do Nordeste.
A produção leiteira no Brasil passou por importantes fases produtivas até a sua consolidação. Salienta-se que este setor até o fim da década de 1980 foi prejudicado. Este período foi marcado pela inserção dos interesses internacionais no campo brasileiro e ações desenvolvidas pelo Estado, visando a expansão agrícola. Além disso, havia o tabelamento do preço do litro do leite, prejudicando a evolução desta atividade, gerando reflexo no processo de produção, resultando na baixa inserção de aparatos técnicos e tecnológicos.

Entretanto, a partir da década de 1990 houve o crescimento deste setor no país, resultado da expansão da necessidade deste produto no mercado interno e externo. Neste sentido, destaca-se que o sistema agroindustrial leiteiro passou por mudanças importantes. Jank; Galan (1997, p. 199) enfatizam,

O sistema agroindustrial do leite brasileiro sofreu profundas mudanças de caráter estrutural desde a virada dos anos 90. Primeiro, veio a desregulamentação do mercado logo no início do Governo Collor, liberando os preços do produto após mais de quatro décadas de controle estatal. Simultaneamente, ocorreu a abertura comercial ao exterior e a consolidação do Mercosul, que representaram um incremento da concorrência com produtos importados.

A produção de leite, nesta perspectiva, passou por um significativo incremento (JANK; GALAN, 1997). Contudo, “[...] o País também se posiciona como grande importador de produtos lácteos, principalmente de leite em pó integral (maior do mundo), leite em pó desnatado, queijos, manteiga e até leite longa vida" (JANK; GALAN, 1997, p. 199).

Mesmo diante do cenário de dificuldades deste setor, vale ressaltar que, "A Cadeia Agroindustrial do Leite se configura como uma das mais importantes do agronegócio brasileiro, tanto sob a ótica econômica como social" (CAMPOS; PIACENTI, 2007, p.9). Considerando ainda questão econômica, Gobbi (2006, p. 34) transcreve,

A produção de leite envolve vários setores $d a$ economia. De um lado, abrange agroindús- 
trias produtoras de uma série de derivados lácteos industrializados, que utilizam o leite como matéria-prima básica, e, de outro, as indústrias de insumos e máquinas que são adquiridas pelos produtores de leite e indústrias de laticinios. Há, ainda, o setor informal, no qual é estabelecida uma relação direta de compra e venda entre consumidor e produtor.

Ressalta-se que esta atividade é essencial no panorama agropecuário brasileiro, pois a mesma auxilia na manutenção da mão de obra rural, fixação do homem no campo, garantindo a geração de renda (CAMPOS; PIACENT, 2007). Portanto, verifica-se a importância desta atividade no cenário econômico nacional. Gobbi (2006, p. 38) aponta,

\section{[...] pode-se observar que o setor leiteiro mostra um comportamento representativo da economia brasileira, tanto na década de 1980, quando as politicas econômicas estavam voltadas para o controle da inflação, quanto na década de 1990, em que o setor passou por sérias mudanças estruturais decorrentes de fatores tais como: abertura econômica via globalização e Mercosul, estabilização econômica proporcionada pelo Plano Real e fim do tabelamento de preço.}

Contudo, diante o panorama de evolução desta produção, Campos; Piacenti (2007, p. 4) assinalam ainda a necessidade de um melhor conhecimento deste setor, pois " [...] a partir da sua caracterização pode-se traçar novos direcionamentos e projeções futuras para a pecuária, propiciando melhor tomada de decisão e superação de entraves que impedem o desenvolvimento da atividade".

Verifica-se a importância da cadeia produtiva do leite no processo de organização/reorganização socioespacial brasileira, a qual atua como dinamizadora no alicerce econômico do país. Entretanto, observa-se que ainda há necessidade de melhoria no processo de produção, sobretudo para atender a necessidade tanto do crescente mercado interno, quanto do exigente mercado consumidor externo.

\section{O DESENVOLVIMENTO DA CADEIA PRODU- TIVA DO LEITE EM ITUIUTABA E OS REFLE- XOS NA ORGANIZAÇÃO/REORGANIZAÇÃO SOCIOESPACIAL LOCAL}

O processo de desenvolvimento espacial, econômico e social de Ituiutaba se confunde com o princípio das atividades desenvolvidas em grande parte do território brasileiro. Utilizaram-se os recursos naturais como condição imprescindível para a ocupação do espaço e evolução das atividades comerciais de produtos do campo.

A metamorfose socioespacial desta unidade territorial está atrelada às atividades vinculadas ao espaço rural. Neste sentido, salienta-se a exploração do solo no início do século XX por meio da extração mineral, posteriormente, entre 1930 a 1970, ocorreu grande produção de arroz, atuando como fundamental dinamizador socioespacial (OLIVEIRA, 2003). Concomitantemente, a pecuária bovina se desenvolvia.

A partir da década de 1970 iniciou-se a expansão produtiva do leite bovino, pois de acordo com o IBGE (2013), houve um aumento da produção de leite de 325,3\% entre 1975 a 2013 em Ituiutaba. Tal incremento produtivo proporcionou a sua reorganização socioespacial. Esta pode ser verificada frente a redução da área cultivada de arroz, uma vez que, o mesmo entre 1970 a 1980 diminuiu a área plantada em 55,9\%. Em contrapartida, neste mesmo período, houve o crescimento da área destinada a pastagem plantada de $274,3 \%$, aumentando também o número de bovinos em 98,7\% (IBGE, 1970/1980), bem como, o número de vacas ordenhadas, $249,1 \%$, entre 1974 e 1984 (IBGE, 2013).

A partir da década de 1980, período que houve desenvolvimento de políticas públicas voltadas para a expansão da atividade agrícola no interior do território brasileiro, principalmente, relacionado às áreas de Cerrado (Bioma predominante em Ituiutaba), articularam-se ações de cunho público, visando atender os interesses internacionais, como do Japão, proporcionando a inserção do cultivo de soja. De acordo com Pessôa (1988, p. 8) o Programa de Cooperação Nipo-Brasileira para o Desenvolvimento dos Cerrados - PRODECER, 
As metamorfoses socioespaciais resultantes do incremento da produção de leite: uma análise desta atividade no município de Ituiutaba/MG no período de 1960 a 2013

Thales Silveira Souto, Meri Lourdes Bezzi

[...] mais conhecido como Projeto Cerrado ou JICA (JAPAN INTERNATIONAL COOPERATION AGENCY), o Estado e o capital internacional produziram uma nova região para atender o mercado internacional, com os elementos básicos ao processo de desenvolvimento: terras, crédito e infra-estrutura (expressa sob a forma de armazenamento, comercialização, assistência técnica, condições de moradia, máquinas, implementos e insumos agricolas).

Neste contexto, houve a expansão da área destinada a esta cultura. Em Ituiutaba de acordo com o Censo Agropecuário do IBGE (1980; 2006) houve um aumento da área plantada em hectares desta leguminosa de 233,9\% entre 1980 a 2006.

Ainda no viés de expansão agrícola, salienta-se o cultivo de cana de açúcar. Esta no início do século XXI obteve um aumento produtivo vinculado, principalmente, as ações públicas, as quais também visavam o interesse do capital, resultando a instalação de unidades transformadoras desta matéria prima em açúcar e etanol. Neste cenário, aponta-se o Programa Nacional do Álcool, o qual de acordo com Sampaio (2011, p. 7),

[...] foi um programa de substituição dos combustiveis derivados de petróleo por álcool, financiado pelo governo do Brasil a partir de 1975 por conta da crise do petróleo em 1973 e 1979, além do baixo preço do açúcar. Com a retomada do preço do açúcar e baixa da gasolina, o programa é praticamente abandonado, voltando à tona nas décadas de 1990, por ser o álcool menos poluente e a criação de automóveis bicombustíveis.

Salienta-se que, em função da facilitação da implantação das indústrias processadoras desta cultura, bem como, referente aos aspectos físicos desta área, como relacionado aos atributos do solo, clima e, até mesmo, de localização geográfica, houve o crescimento do cultivo desta gramínea. Sendo que, em Ituiutaba, entre 2000 a 2013 a área plantada aumentou $4050 \%$ (IBGE, 2013).

Visando compreender o incremento produtivo leiteiro em Ituiutaba e a importância deste setor no cenário agropecuário local, bem como, a atual situação desta atividade, frente a expansão produtiva das principais culturas, as quais relacionam-se a soja e a cana de açúcar, faz-se fundamental verificar a atuação produtiva do leite diante o panorama agropecuário. Para tanto, analisou-se na escala temporal desta investigação, o uso do solo para pastagem, a quantidade de leite produzido, comparando ao número de vacas ordenhadas, visualizando o panorama referente a produtividade.

Tendo em vista analisar as dinâmicas agropecuárias desta unidade territorial, deve-se considerar as transformações produtivas e espaciais resultantes. $\mathrm{Na}$ Tabela 01 apresenta-se a área plantada das principais culturas nesta unidade territorial, no período de 1960 a 2013.

Tabela 01 - Principais cultivos realizados no município de Ituiutaba/MG (1960 a 2013)

\begin{tabular}{|c|c|c|c|c|c|c|c|}
\hline & 1960 & 1970 & 1980 & 1990 & 1996 & 2006 & $\mathbf{2 0 1 3}$ \\
\hline Algodão & - & 2.449 & 561 & 1.996 & 1.630 & 100 & - \\
\hline Arroz & 17.373 & 19.526 & 8.615 & 3.403 & 3.750 & 50 & 50 \\
\hline Cana de açúcar & 81 & 63 & 144 & 400 & 400 & 7.200 & 21.000 \\
\hline Feijão & 3.149 & 1.521 & 33 & 172 & 10 & - & - \\
\hline Sorgo & - & - & - & 400 & 300 & 650 & 6.000 \\
\hline Milho & 11.580 & 12.236 & 10.626 & 10.000 & 7.000 & 8.000 & 3.300 \\
\hline Soja & 0 & 0 & 2.096 & 3.000 & 2.500 & 7.000 & 11.600 \\
\hline
\end{tabular}

Fonte: Censo Agrícola do IBGE, 1960/Censos Agropecuários, 1970, 1980, 1996 e 2006/SIDRA, 2013.

Org.: dos Autores, 2015. 
As metamorfoses socioespaciais resultantes do incremento da produção de leite: uma análise desta atividade no município de Ituiutaba/MG no período de 1960 a 2013

Thales Silveira Souto, Meri Lourdes Bezzi

Salienta-se que, a consequência da redução da área destinada ao arroz, que foi a principal atividade agrícola até meados da década de 1970, bem como, do milho, algodão e feijão, relacionam-se a alguns fatores, como, o crescimento da área destinada a pastagem plantada, que por sua vez, é proveniente do crescimento do número de gado, demandado para a produção leiteira, tendo como principal forneci- mento, a indústria da Nestlé (a partir de 1974), bem como, referente a fatores de caráter externo, os quais proporcionaram a dinamização do setor agropecuário, referindo-se ao reflexo do período de crise econômica, como também, à necessidade de expansão da produção de culturas comerciais no cenário mundial (soja). Neste contexto, salienta-se o crescimento da pecuária de leite (Gráfico 01).

Gráfico 01 - Evolução da quantidade produzida de leite em mil litros no município de Ituiutaba/MG (1960 a 2013)

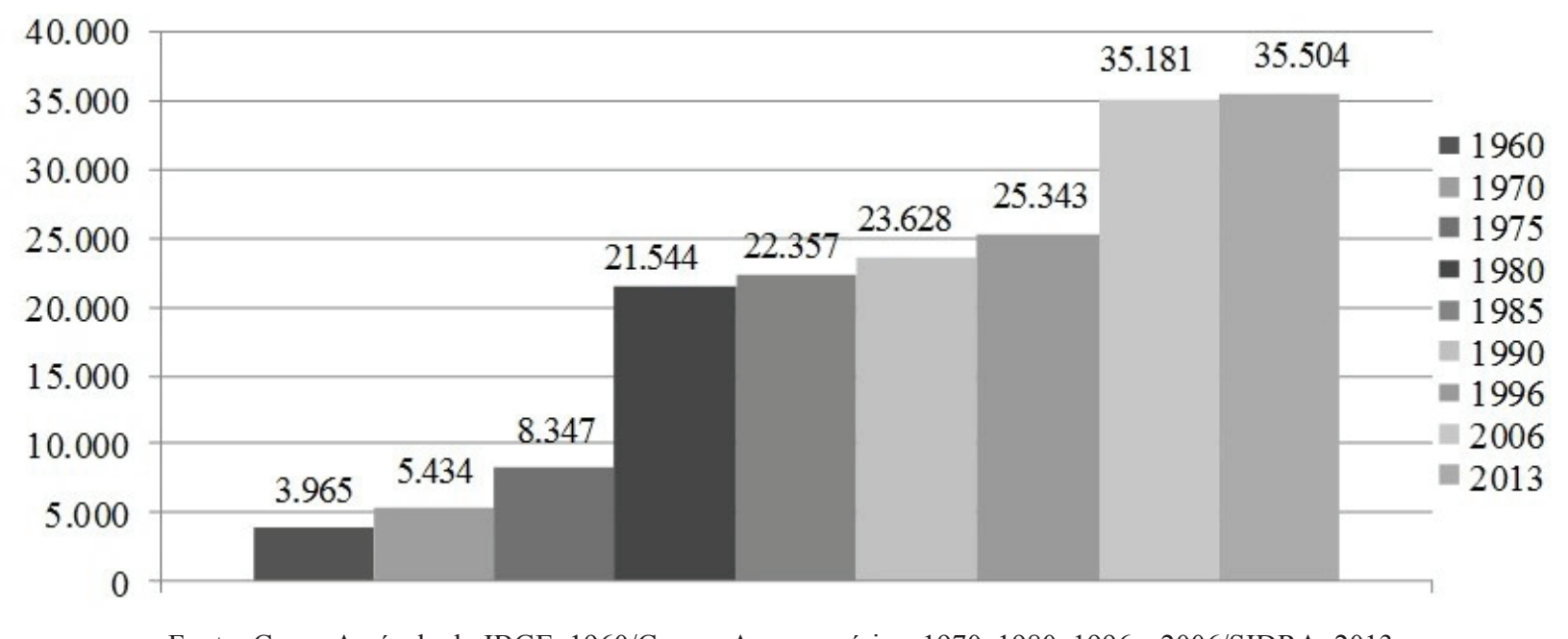

Fonte: Censo Agrícola do IBGE, 1960/Censos Agropecuários, 1970, 1980, 1996 e 2006/SIDRA, 2013.

Org.: dos Autores, 2015.

Observou-se que, o crescimento da produção de leite nesta unidade territorial é consequência da expansão da demanda das fábricas de derivados de leite de Ituiutaba, bem como, devido a necessidade deste produto para atendimento das agroindústrias dos municípios limítrofes.

Paralelamente, a utilização do solo para a pastagem é fator essencial que demonstra o cenário referente a esta produção. De acordo com dados do IBGE (2013), salienta-se o crescimento da utilização da pastagem plantada de 78,4\% entre os anos de 1975 e 1980. Em contrapartida, houve a redução da utilização da pastagem natural de $43 \%$ neste mesmo período. Salienta-se a redução do uso de pastagem natural de 162,6\% em 1996 se comparado ao ano de 1980. Já a utilização de pastagem plantada entre 1980 e 1996 aumentou $44 \%$. No que tange a redução da utilização de pastagem plantada em 2006 se comparado a 1996, foi em consequência da expansão de algumas culturas como a cana de açúcar.

A redução da utilização da pastagem natural é substancialmente considerada devido a exploração do Cerrado (a partir da década de 1960) para o plantio das culturas comerciais (soja, milho e cana de açúcar). Conjuntamente, a produção de alimentos para o consumo do gado, também teve crescimento, destacando-se o cultivo de milho, soja, sorgo, cana de açúcar, entre outros, bem como, devido a necessidade de manejo do solo para melhor e maior produtividade, o qual, torna-se cada vez mais essencial, resultando o crescimento da utilização de área com pastagem plantada, frente a redução da utilização de área com pastagem natural. Tal fato pode ser justificado devido a necessidade de engorda com qualidade do gado, gerando tanto para 
As metamorfoses socioespaciais resultantes do incremento da produção de leite: uma análise desta atividade no município de Ituiutaba/MG no período de 1960 a 2013

Thales Silveira Souto, Meri Lourdes Bezzi

o gado de corte, quanto para o gado de leite, maior rendimento.

Considerando a realidade vivenciada pelos produtores de leite deste município, salienta-se a coleta de informações primárias, as quais foram resultado das entrevistas efetivadas no trabalho de campo. Neste sentido, buscou-se compreender os entraves, as perspectivas, averiguando a expansão, bem como, a estagnação desta atividade no cenário produtivo agropecuário desta unidade territorial.

No que tange a variável relacionada a quantidade de vacas em produção nos estabelecimentos produtores de leite de Ituiutaba, observa-se na Tabela 02 sua distribuição percentual.

Tabela 02 - Distribuição percentual do número de estabelecimentos produtores de leite com a quantidade de vacas em produção no município de Ituiutaba/MG

\begin{tabular}{|c|c|}
\hline Quantidade de vacas em produção & Estabelecimentos (\%) \\
\hline 1 a 10 & $3,1 \%$ \\
\hline 11 a 20 & $23,4 \%$ \\
\hline 21 a 30 & $26,6 \%$ \\
\hline 31 a 40 & $18,5 \%$ \\
\hline 41 a 50 & $10,3 \%$ \\
\hline Mais de 51 & $17,2 \%$ \\
\hline Total & $\mathbf{1 0 0 \%}$ \\
\hline
\end{tabular}

Fonte: Trabalho de campo realizado nos estabelecimentos produtores de leite de Ituiutaba/MG, 2015.

Org.: dos Autores, 2015.

Dos produtores entrevistados, verificou-se que $71,8 \%$ possuem menos de 41 vacas em produção. Neste viés, salienta-se o panorama referente a produção de leite no município. De acordo com a entrevista realizada no trabalho de campo, verificou-se a percentagem da produção por dia da quantidade de litros de leite por estabelecimento em Ituiutaba (Tabela 03).

Tabela 03 - Percentagem da produção/dia de leite por estabelecimento no município de Ituiutaba/MG

\begin{tabular}{|c|c|c|}
\hline Quantidade de litros produzidos por dia por produtor & Quantidade de Estabelecimento & Produção (\%) \\
\hline 1 a 100 & 18 & $28,1 \%$ \\
\hline 101 a 200 & 20 & $31,2 \%$ \\
\hline 201 a 300 & 8 & $12,5 \%$ \\
\hline 301 a 400 & 3 & $4,7 \%$ \\
\hline 401 a 500 & 2 & $3,1 \%$ \\
\hline 501 a 600 & 5 & $7,8 \%$ \\
\hline 601 a 700 & 2 & $3,1 \%$ \\
\hline 701 a 800 & 2 & $3,1 \%$ \\
\hline Mais de 801 & 4 & $6,2 \%$ \\
\hline Total & $\mathbf{6 4}$ & $\mathbf{1 0 0 \%}$ \\
\hline
\end{tabular}

Fonte: Trabalho de campo realizado nos estabelecimentos produtores de leite de Ituiutaba/MG, 2015.

Org.: dos Autores, 2015. 
As metamorfoses socioespaciais resultantes do incremento da produção de leite: uma análise desta atividade no município de Ituiutaba/MG no período de 1960 a 2013

Thales Silveira Souto, Meri Lourdes Bezzi

Analisando a tabela 03, ressalta-se a quantidade de produtores que, em sua maioria, produzem por dia entre 1 a 100 litros e 101 a 200 litros, os quais, correspondem ao total de $59,4 \%$ de toda a produção leiteira desta unidade territorial, isto referente a amostra estabelecida nesta pesquisa.

De acordo com a entrevista $66,6 \%$ das agroindústrias possuem fornecedores de leite referentes ao pequeno e ao médio produtor e, 33,4\% responderam que seus fornecedores são pequenos, médios e grandes produtores. Verificou-se que o pequeno e médio produtor de leite são importantes para a manutenção do setor leiteiro nesta unidade territorial. Nesta perspectiva, observa-se a área em hectares (ha) dos estabelecimentos agropecuários produtores de leite em Ituiutaba (Tabela 04).

Tabela 04 - Área em hectares (ha) do estabelecimento produtor de leite no município de Ituiutaba/MG

\begin{tabular}{|c|c|c|c|}
\hline $\begin{array}{c}\text { Área (ha) do estabelecimento } \\
\text { produtor de leite - 10 a menos de } \\
\mathbf{1 0 0} \text { há }\end{array}$ & $\begin{array}{c}\text { Estabelecimento } \\
\mathbf{( \% )}\end{array}$ & $\begin{array}{c}\text { Área (ha) do estabeleci- } \\
\text { mento produtor de leite - } \\
\mathbf{1 0 0} \text { a menos de } \mathbf{1 0 0 0} \text { ha }\end{array}$ & $\begin{array}{c}\text { Estabelecimento } \\
\mathbf{( \% )}\end{array}$ \\
\hline 10 a 20 & $39 \%$ & 101 a 200 & $3,2 \%$ \\
\hline 21 a 50 & $42,2 \%$ & 201 a 500 & $6,2 \%$ \\
\hline 51 a 100 & $7,8 \%$ & 501 a 1000 & $1,6 \%$ \\
\hline Total & $\mathbf{8 9 \%}$ & & $\mathbf{1 1 \%}$ \\
\hline
\end{tabular}

Fonte: Trabalho de campo realizado nos estabelecimentos produtores de leite de Ituiutaba/MG, 2015.

Org.: dos Autores, 2015.

No que tange a área do estabelecimento agropecuário produtor nesta unidade territorial, ressalta-se que $39 \%$ possuem de 10 a 20 (ha) e $42,2 \%$ possuem entre 21 a 50 (ha). Neste sentido, verificou-se que, a maioria dos produtores de leite encontram-se no estrato de área entre 10 e 50 ha, ou seja, $81,2 \%$, caracterizando a relevância destes estabelecimentos. Relacionando a tabela 4 à 3 (a qual refere-se a quantidade de litros de leite produzido por dia) averiguou-se a importância dos pequenos e médios produtores.

Neste sentido, mesmo apresentando dificuldades na produção desta matéria prima, vale ressaltar os principais fatores que contribuíram para o aumento da produtividade do leite, entre esses, destacam-se a melhoria na alimentação do animal vinculado ao uso de ração, manejo do pasto, utilização de complementos alimentares capazes de oferecer maior rendimento à produção leiteira, como o milho, a silagem, entre outros e, devido à melhoria da infraestrutura dos estabelecimentos, como o uso de cochos adequados para melhor indução do animal à alimentação, a instalação da ordenha mecanizada, utilização de tanques refrigeradores para armazenamento do leite, melhorias nas técnicas do trato e até mesmo o conforto do animal. Salienta-se a utilização de métodos e equipamentos para o crescimento da produtividade no município em estudo (Tabela 05). 
As metamorfoses socioespaciais resultantes do incremento da produção de leite: uma análise desta atividade no município de Ituiutaba/MG no período de 1960 a 2013

Thales Silveira Souto, Meri Lourdes Bezzi

Tabela 05 - Equipamentos, tecnologias e trato da vaca dos estabelecimentos produtores de leite de Ituiutaba/MG

\begin{tabular}{|c|c|}
\hline Equipamentos, tecnologias e trato do animal & Percentagem de estabelecimentos (\%) \\
\hline Ordenha mecânica & $39 \%$ \\
\hline Tanque refrigerador & $100 \%$ \\
\hline Utilização de ração comprada & $100 \%$ \\
\hline Inseminação artificial & $26,6 \%$ \\
\hline
\end{tabular}

Fonte: Trabalho de campo realizado nos estabelecimentos produtores de leite de Ituiutaba/MG, 2015.

Org.: dos Autores, 2015.

Aponta-se que a suplementação alimentar utilizada é um fator essencial para a melhoria da produtividade do animal, a qual proporciona maior nutrição, complementando as exigências necessárias para maior e melhor produção da vaca (Tabela 06).

Tabela 06 - Variável da complementação na alimentação das vacas em Ituiutaba/MG

\begin{tabular}{|c|c|}
\hline Complementos utilizados na alimentação da vaca & Estabelecimentos (\%) \\
\hline Casquinha de soja & $23,4 \%$ \\
\hline Cana de açúcar & $25 \%$ \\
\hline Milho & $10,9 \%$ \\
\hline Sal Mineral & $21,9 \%$ \\
\hline Polpa cítrica & $3,1 \%$ \\
\hline Sorgo & $6,2 \%$ \\
\hline Proteinado & $1,6 \%$ \\
\hline Não utiliza & $7,8 \%$ \\
\hline
\end{tabular}

Fonte: Trabalho de campo realizado nos estabelecimentos produtores de leite de Ituiutaba/MG, 2015.

Org.: dos Autores, 2015.

Nos estabelecimentos que foram realizadas as entrevistas, verificou-se que, em sua maioria, a produtividade tem aumentado. Para melhor compreensão do cenário produtivo leiteiro referiu-se ao ano 2000. Entre os motivos para a definição de 2000, como período de análise desta arguição, considerou-se o início da expansão do cultivo de cana de açúcar na Microrregião de Ituiutaba, bem como do município de
Ituiutaba/MG. Salienta-se que, de acordo com dados do SIDRA/IBGE (2015), entre 1990 e 2000 houve um crescimento da área plantada desta cultura nesta unidade territorial de apenas $25 \%$. Em contrapartida, entre 2000 e 2013, o aumento da área plantada de cana de açúcar foi de $4050 \%$, utilizando-se áreas antes destinadas a outros cultivos, como a pastagem (Tabela 07). 
As metamorfoses socioespaciais resultantes do incremento da produção de leite: uma análise desta atividade no município de Ituiutaba/MG no período de 1960 a 2013

Thales Silveira Souto, Meri Lourdes Bezzi

Tabela 07 - Variável relacionada a produtividade leiteira dos produtores do município de Ituiutaba/MG

\begin{tabular}{|c|c|}
\hline Produtividade do leite & Estabelecimentos (\%) \\
\hline Aumentou & $51,6 \%$ \\
\hline Reduziu & $6,2 \%$ \\
\hline Manteve-se & $18,7 \%$ \\
\hline Não produzia antes de 2000 & $23,4 \%$ \\
\hline
\end{tabular}

Fonte: Trabalho de campo realizado nos estabelecimentos produtores de leite de Ituiutaba/MG, 2015.

Org.: dos Autores, 2015.

A partir do período especificado para análise (2000), observou-se que a produtividade tem aumentado em 51,6\% dos estabelecimentos entrevistados, ao passo que $6,2 \%$ consideram ter diminuído, $18,7 \%$ responderam que a mesma manteve-se, enquanto $23,4 \%$ não produziam leite antes de 2000 . Em relação aos produtores que começaram a produzir leite após 2000 , ressalta-se que, em sua maioria, referem-se aos assentados. Dentre os fatores que favoreceram o aumento da produtividade, salienta-se, principalmente, os relacionados às melhorias realizadas no processo de produção e coleta do leite in natura.

Contudo, algumas adversidades prejudicam a produção do leite, bem como a manutenção e evolução do produtor frente as demais atividades (Tabela 08).

Tabela 08 - Adversidades que atrapalham o produtor leiteiro de Ituiutaba/MG

\begin{tabular}{|c|c|}
\hline Adversidades que prejudicam a pecuária leiteira & Percentagem (\%) \\
\hline Seca & $23,4 \%$ \\
\hline Falta de amparo técnico & $7,8 \%$ \\
\hline Queda no valor do leite pago pelas agroindústrias & $54,7 \%$ \\
\hline Falta de mão de obra & $6,2 \%$ \\
\hline Falta de apoio financeiro e crédito & $3,1 \%$ \\
\hline Ração, suplementação alimentar, equipamentos caros & $4,7 \%$ \\
\hline
\end{tabular}

Fonte: Trabalho de campo realizado nos estabelecimentos produtores de leite de Ituiutaba/MG, 2015.

Org.: dos Autores, 2015.

Entre os principais problemas enfrentados pelos produtores, a queda no valor do produto, é a principal reclamação. Destaca-se a fala de alguns entrevistados: "O valor pago pelo litro do leite, muitas vezes, não cobre as despesas". Outro entrevistado salienta: "Daqui a alguns dias não poderemos continuar produzindo leite, o preço pago pelo laticínio cada vez mais está diminuindo". Um entrevistado, destacou: "Deveriam aumentar o valor pago pelo litro do leite, desse jeito poderiam aumentar a qualidade do produto final, pois assim, iríamos conseguir investir na propriedade e na produção".

Deste modo, buscou-se a média do valor pago pelas agroindústrias leiteiras que captam leite dos estabelecimentos visitados no campo (Tabela 09). 
As metamorfoses socioespaciais resultantes do incremento da produção de leite: uma análise desta atividade no município de Ituiutaba/MG no período de 1960 a 2013

Thales Silveira Souto, Meri Lourdes Bezzi

Tabela 09 - Variável do valor pago pelas agroindústrias leiteiras de Ituiutaba/MG ao leite in natura

\begin{tabular}{|c|c|}
\hline $\begin{array}{c}\text { Valor pago pelo leite } \text { in natura } \\
\text { Preço RS }\end{array}$ & $\begin{array}{c}\text { Percentagem } \\
\text { (\%) }\end{array}$ \\
\hline 0,71 a 0,90 & $34,4 \% \%$ \\
\hline 0,91 a 1,10 & $65,6 \%$ \\
\hline Total & $\mathbf{1 0 0 \%}$ \\
\hline
\end{tabular}

Fonte: Trabalho de campo realizado nos estabelecimentos produtores de leite de Ituiutaba/MG, 2015.

Org.: dos Autores, 2015.

Ressalta-se o valor pago pelo litro do leite de acordo com a publicação pelo Centro de Estudos Avançados em Economia Aplicada - CEPEA/Escola Superior de Agricultura "Luiz de Queiros" - ESALQ/ Universidade de São Paulo - USP. Segundo Campos; Neves (2007) O CEPEA foi criado em 1982 pelos docentes do Departamento de Economia, Administração e Sociologia (DEAS) da Esalq, o qual tem o objetivo de desenvolver estudos, pesquisas nas áreas da Economia, Administração e Ciências Sociais. Em relação ao leite, de acordo com Campos; Neves (2007, p. 104) “[...] o CEPEA possui o Boletim do Leite, que já tem doze anos de publicação. Este boletim informa, com a ajuda de parceiros dentro do sistema, vários dados relativos a todo seu sistema agroindustrial, propiciando uma visão geral do mercado do leite". (Tabela 10).

Tabela 10 - Preço (R\$) pago pelos laticínios (brutos) ao produtor de leite (líquidos) em janeiro de 2015 referentes ao leite entregue em dezembro de 2014

\begin{tabular}{|c|c|c|c|c|c|c|c|c|}
\hline Área & \multicolumn{2}{|c|}{$\begin{array}{c}\text { Preço Bruto } \\
\text { Inclusos frete e CESSR (ex- } \\
\text {-Funrural - Fundo de Assistên- } \\
\text { cia do Produtor Rural) }\end{array}$} & \multicolumn{3}{|c|}{ Preço Líquido } & \multicolumn{2}{|c|}{$\begin{array}{c}\text { Val \% } \\
\text { Bruto }\end{array}$} & $\begin{array}{c}\text { Val \% } \\
\text { Líquido }\end{array}$ \\
\hline Mesorregião & Máximo & Mínimo & Médio & Máximo & Mínimo & Médio & jan./dez. & jan./dez. \\
\hline $\begin{array}{c}\text { Triângulo } \\
\text { Mineiro/Alto } \\
\text { Paranaíba }\end{array}$ & 1,0595 & 0,8484 & 0,9594 & 0,9739 & 0,7676 & 0,7676 & $-7,42 \%$ & $-7,96 \%$ \\
\hline
\end{tabular}

Fonte: Boletim do leite (Centro de Estudos Avançados em Economia Aplicada - CEPEA/Escola Superior de Agricultura "Luiz de Queiros" - ESALQ/Universidade de São Paulo - USP), 2015.

Org.: dos Autores, 2015.

Comparando a tabela 09, a qual apresenta o resultado referente a variável do valor pago pelo litro do leite aos produtores entrevistados no campo, a tabela 10, o qual é fonte da tabela de preços pagos pelos laticínios aos produtores, realizado pelo CEPEA, verifica-se que há uma aproximação no resultado obtido no campo, ou seja, por meio da realização das entrevistas, verificou-se que, $34,4 \%$ dos entrevistados responderam que os laticínios pagaram em média no ano de 2014 entre R\$ 0,71 a 0,90 centavos. No que tange o quadro do CEPEA, visualiza-se que o preço mínimo líquido é de R \$ O,7676 a máximo de 0,9739 centavos (referente a produção apenas de dezembro de 2014). Entre os entrevistados que corresponderam à percentagem estabelecida pela pesquisa do CEPEA, observa-se que há certa representatividade do cumprimento pelos laticínios do valor a ser pago pelo leite. Ressalta-se ainda que, $65,6 \%$ dos entrevistados responderam que em média no ano de 2014, os laticínios pagaram entre $\mathrm{R} \$ 0,91$ a 1,10 pelo litro do leite. Este resultado, deve-se à média anual, no entanto, deve-se salientar que a diferença paga pelo litro do 
As metamorfoses socioespaciais resultantes do incremento da produção de leite: uma análise desta atividade no município de Ituiutaba/MG no período de 1960 a 2013

Thales Silveira Souto, Meri Lourdes Bezzi

leite refere-se a alguns aspectos, como por exemplo, a qualidade do leite, a quantidade produzida, assim como, a prioridade de cada agroindústria no que tange as políticas e organizações internas.

Neste sentido, procurou-se entender o que os entrevistados acham da atuação dos laticínios no auxílio, manutenção e valorização do produtor. Assim, $54,7 \%$ dos entrevistados responderam que os laticínios valorizam a atividade, a qual é permeada pela assistência técnica, oferta de crédito e empréstimo a baixos juros, organização de eventos e palestras para aumentar o repasse de informações essenciais para melhor qualidade do produto in natura e, também, para maior produtividade. Já 45,3\% disseram que os laticínios não valorizam a atividade, visto que as reclamações destes produtores alicerçam-se, principalmente ao valor pago pelo litro do leite, o que impossibilita a realização de investimentos no estabelecimento, dificultando o desenvolvimento dos mesmos no setor.

Analisando a fala dos entrevistados, verificou-se a falta de incentivos, principalmente públicos, para a realização de financiamentos com juros baixos e com maior prazo voltado para este setor da economia. Através da realização das entrevistas e conversas informais com os produtores, constataram-se diversas reclamações a respeito do pouco apoio governamental em nível municipal, estadual e federal, bem como, das instituições de pesquisa e fomento da atividade agropecuária.

Para o conhecimento do processo de captação do leite, realizou-se entrevistas estruturadas por um questionário às agroindústrias instaladas nesta unidade territorial. Os dados coletados foram imprescindíveis para a análise da importância destas fábricas para a manutenção do setor leiteiro na atualidade. De acordo com a Fazendeira, capta-se em média 20.000 litros por dia, totalizando 51 fornecedores, os quais não restringem-se apenas a Ituiutaba, pois produtores de Gurinhatã/MG, Capinópolis/MG e Ipiaçu/MG, também atendem a demanda. Já o Canto de Minas, coleta em média 70.000 litros por dia, tendo o total de 150 fornecedores, os quais são de Capinópolis, Gurinhatã e Ituiutaba. Em relação à Nestlé, esta possui capacidade de transformação de 2.000.000 litros por dia, no entanto, em média tem-se coletado cerca de 1.800.000 litros por dia, tendo 280 fornecedores. Salienta-se que a Nestlé por ser uma fábrica de grande porte, possui uma rede de coleta do leite que envolve um raio de cerca de $180 \mathrm{~km}$ da fábrica, incluindo além de Ituiutaba, os municípios de Uberlândia/MG, Cachoeira Dourada/MG, Campina Verde/MG e São Simão/GO (Trabalho de campo, 2015).

$\mathrm{Na}$ Tabela 11, apresenta-se a variável correspondente às agroindústrias que captam leite dos produtores de Ituiutaba, os quais foram entrevistados no trabalho de campo.

Tabela 11 - Variável das agroindústrias que captam leite dos produtores de Ituiutaba/MG

\begin{tabular}{|c|c|}
\hline Agroindústria que capta o leite in natura & Percentagem (\%) \\
\hline Nestlé & $46,9 \%$ \\
\hline Canto de Minas & $35,9 \%$ \\
\hline Fazendeira & $17,2 \%$ \\
\hline Total & $\mathbf{1 0 0} \%$ \\
\hline
\end{tabular}

Fonte: Trabalho de campo realizado nos estabelecimentos produtores de leite de Ituiutaba/MG, 2015.

Org.: dos Autores, 2015.

A Nestlé por se caracterizar como a indústria leiteira com maior expressividade no município, consequentemente, possui o maior número de fornecedores. Neste sentido, ressalta-se a importância que esta indústria possui no cenário produtivo agropecuário de Ituiutaba.
A realização da entrevista aos órgãos gestores e mantenedores do setor agropecuário de Ituiutaba, proporcionou a compreensão dos aspectos relacionados a importância deste para o município, frente as demais atividades. Assim, na pergunta que se referia à principal atividade econômica desenvolvida nesta 
As metamorfoses socioespaciais resultantes do incremento da produção de leite: uma análise desta atividade no município de Ituiutaba/MG no período de 1960 a 2013

Thales Silveira Souto, Meri Lourdes Bezzi

unidade territorial, tanto a Secretaria de Agricultura Pecuária e Abastecimento, quanto o Sindicato dos Produtores Rurais de Ituiutaba (SIPRI) e o Sindicato do Trabalhador Rural (STR) apontaram a pecuária. Já de acordo com a EMATER - MG, a pecuária é importante, mas deve-se destacar a relevância das agroindústrias existentes no município, até porque, por meio dessas ocorre a geração de emprego e renda.

Informações importantes foram obtidas com o secretário da agricultura, pois ele salientou que, "As maiores indústrias do município giram em torno da produção do leite. Um exemplo é a Nestlé, que por dia tem capacidade de produzir 2.000 .000 de litros de leite. Outro exemplo, envolvendo a pecuária, relaciona-se ao frigorifico JBS (pecuária de corte)". Em relação ao SIPRI, salientou, "Ela (pecuária leiteira) que fomenta o agronegócio. A principal renda é a pecuária. Além disso, é responsável por grande parte da geração de emprego e renda do município". Já o extensionista da EMATER, considera, "Esse setor é responsável pela geração de emprego e renda. Destaco a questão climática, pois é favorável para a pecuária. Em relação a atividade agrícola, muitas vezes a falta de chuva pode ser prejudicial". De acordo com o presidente do STR, "A pecuária de leite é muito importante, pois gera emprego e consequentemente, renda. Destacam-se os assentamentos que criaram uma associação dos produtores de leite, permitindo competitividade. O melhor valor do leite de Ituiutaba provém dessa associação" (Trabalho de campo, 2015).

No que tange ao atual cenário empresarial agropecuário, o qual refere-se a comercialização dos produtos nos estabelecimentos produtores de leite de Ituiutaba, ressalta-se que $50 \%$ das empresas entrevistadas consideram que desde a inauguração da empresa as vendas estão em crescente aumento. Por outro lado, $50 \%$ responderam que está havendo uma redução nos últimos anos. Tal assertiva pode ser constatada na resposta de um empresário: "Está estagnada as vendas. $\mathrm{O}$ baixo valor pago pelo litro do leite aos produtores reduz o poder de compra e, por consequência, a realização de maiores investimentos na propriedade". Considerando as entrevistas, pôdese também compreender que, mediante a expansão de determinadas atividades agrícolas em Ituiutaba, como a expansão do cultivo de cana de açúcar (a partir de
2000), houve o arrendamento de parcelas de algumas propriedades às usinas sucroalcooleiras, gerando renda aos produtores de leite, fomentando o processo de melhorias relacionadas ao pasto, ao rebanho e, também, para o financiamento de tecnologias, aumentando a produtividade, principalmente relacionada à ordenha mecanizada, a utilização dos tanquinhos para refrigerar o leite, armazenando o produto in natura. Tais procedimentos asseguram a qualidade do leite, atendendo as regras da vigilância sanitária.

Outro aspecto que deve ser considerado é em relação a mão de obra no campo. Aponta-se que esta obteve uma considerável redução, tanto relacionado ao homem, quanto à mulher. Observa-se a diminuição da quantidade de pessoal ocupado para as atividades empregatícias nos estabelecimentos agropecuários de Ituiutaba, onde houve a redução de $66,5 \%$ da quantidade de homens ocupados e $54,2 \%$ da quantidade de mulheres em estabelecimentos agropecuários no período de 1960 a 2013 (Censo Agrícola do IBGE, 1960/Agropecuários do IBGE, 1970, 1980, 1996, 2006/Pesquisa Pecuária Municipal, 2013).

No que diz respeito a mão de obra no campo brasileiro esta diminuiu significativamente em função do êxodo rural e do processo de modernização do campo, principalmente a partir da década de 1960 e 1970. Em Ituiutaba, esta realidade é perceptível especialmente quando se analisou os comentários dos produtores, pois através da realização das entrevistas, durante o trabalho de campo, averiguou-se que, muitos proprietários de estabelecimentos agropecuários produtores de leite, reclamaram da deficiência de mão de obra tanto masculina, quanto feminina. Tal fato pode ter resultado o aumento da mecanização das propriedades, como a utilização da ordenha mecânica.

\section{CONSIDERAÇÕES FINAIS}

O setor produtivo agropecuário é fundamental dinamizador socioespacial de Ituiutaba. Neste contexto, ressalta-se a pecuária leiteira, esta, por sua vez, foi essencial no processo de organização/reorganização do cenário produtivo e espacial desta unidade territorial. Deste modo, averiguou-se a importância desta produção, bem como das indústrias de beneficiamento do leite no município como aspectos balizadores das 
As metamorfoses socioespaciais resultantes do incremento da produção de leite: uma análise desta atividade no município de Ituiutaba/MG no período de 1960 a 2013

Thales Silveira Souto, Meri Lourdes Bezzi

metamorfoses espaciais e produtivas.

A partir da implantação da principal agroindústria leiteira em 1974 ocorreu a redução da área plantada de algumas culturas, como referente ao arroz, feijão, algodão, a expansão da utilização do solo para pastagem plantada, o crescimento do número de cabeças de gado leiteiro, bem como do número de vacas ordenhadas, além da questão da mão de obra no campo, salientando as mudanças provenientes do incremento do setor leiteiro no município.

Entretanto, mediante as ações do capital internacional, como por meio do processo de modernização da agricultura atrelada a inserção técnica e tecnológica para aumentar a produção agrícola, houve o redirecionamento do cenário agropecuário para o cultivo de milho, soja e, por último, da cana de açúcar.

Neste contexto, vinculando esta realidade à observação referente ao panorama produtivo do município enfocado, observou-se que a pecuária leiteira mesmo diante à expansão do cultivo de soja, milho e cana de açúcar, têm mantido o crescimento, principalmente da sua produtividade. Assim sendo, verificaram-se metamorfoses resultantes do incremento da produção de leite, as quais manifestam-se na dinâmica da organização/reorganização espacial e produtiva agropecuária desta unidade territorial.

A partir da realização das entrevistas com os sujeitos da pesquisa foi possível a compreensão dos principais entraves, bem como, do atual cenário produtivo do leite em Ituiutaba. Neste sentido, considera-se que a pecuária leiteira representa importância fundamental, isto no que tange a geração de emprego e renda. Por sua vez, fomenta a demanda das agroindústrias, destacando as processadoras de leite existentes no município e nos demais, proporcionando a retroalimentação do capital local.

\section{REFERÊNCIAS}

BARROS, G. S. de C.; ZEN, S. de. Boletim do leite. Centro de Estudos Avançados em Economia Aplicada-CEPEA/Escola Superior de Agricultura Luiz de Queiros - ESAL/Universidade de São Paulo - USP. Ano 21, n. 237, jan. 2015. Disponível em: <http:// cepea.esalq.usp.br/leite/boletim/237.pdf $>$. Acesso em: 10 mar. 2015.
CAMPOS, K. C.; PIACENTI, C. A. Agronegócio do leite: cenário atual e perspectivas. In: XLV Congresso da SOBER, 2007, Londrina. Anais... Londrina: UEL, pp. $1-18,2007$.

CAMPOS, E. M.; NEVES, M. F. Planejamento e gestão estratégica do sistema agroindustrial do leite no estado de São Paulo. São Paulo: SEBRAE, 2007. GIL, A. C. Métodos e técnicas de pesquisa social. $6^{\mathrm{a}}$ ed. São Paulo: Editora Atlas S.A., 2008.

GERARDI, L. H. de O.; SILVA, C. N. Quantificação em geografia. São Paulo: DIFEL, 1981.

GOBBI, W. A. de O. A pecuária leiteira na comunidade da Canoa - Ituiutaba ( $M G$ ): persistência e resistência. 2006. 250 f. Dissertação (Mestrado em Geografia) - Universidade Federal de Uberlândia, Uberlândia, 2006.

INSTITUTO BRASILEIRO DE GEOGRAFIA E ESTATÍSTICA - IBGE. Censo Agrícola de Minas Gerais. Rio de Janeiro, 1960.

INSTITUTO BRASILEIRO DE GEOGRAFIA E ESTATÍSTICA - IBGE. Censo Agropecuário de Minas Gerais. Rio de Janeiro, 1970.

INSTITUTO BRASILEIRO DE GEOGRAFIA E ESTATÍSTICA - IBGE. Censo Agropecuário de Minas Gerais. Rio de Janeiro, 1980.

INSTITUTO BRASILEIRO DE GEOGRAFIA E ESTATÍSTICA - IBGE. Censo Agropecuário de Minas Gerais. Rio de Janeiro, 1996.

INSTITUTO BRASILEIRO DE GEOGRAFIA E ESTATÍSTICA - IBGE. Censo Agropecuário de Minas Gerais. Rio de Janeiro, 2006.

INSTITUTO BRASILEIRO DE GEOGRAFIA E ESTATÍSTICA - IBGE. SISTEMA IBGE DE RECUPERAÇÃO AUTOMÁTICA - SIDRA. Produção Agrícola Municipal de 1990, 2000, 2010. Disponível em: $<\mathrm{http}$ //www.sidra.ibge.gov.br/bda/tabela/listabl.asp? $\mathrm{z}=-$ $\mathrm{t} \& \mathrm{o}=1 \& \mathrm{i}=\mathrm{P} \& \mathrm{e}=1 \& \mathrm{c}=1612>$. Acesso em: 17 jan. 2012. 
As metamorfoses socioespaciais resultantes do incremento da produção de leite: uma análise desta atividade no município de Ituiutaba/MG no período de 1960 a 2013

Thales Silveira Souto, Meri Lourdes Bezzi

INSTITUTO BRASILEIRO DE GEOGRAFIA E ESTATÍSTICA - IBGE. SIDRA. Pesquisa Pecuária Municipal. 2013. Disponível em: $<$ http://www.sidra. ibge.gov.br/bda/pesquisas/ppm/default.asp > . Acesso em: 20 fev. 2015.

INSTITUTO BRASILEIRO DE GEOGRAFIA E ESTATÍSTICA - IBGE. Pesquisa Pecuária Municipal - Dados Gerais. 2013. Disponível em: < http:// www.sidra.ibge.gov.br/bda/acervo/>. Acesso em: 5 dez. 2014.

JANK, M. S.; GALAN, V. B. Competitividade do Sistema agroindustrial do leite. São Paulo: PENSA/ FIA/FEA/USP, 1997.

MAZOYER, M.; ROUDART, L. História das agriculturas no mundo: do neolítico à crise contemporânea. Tradução de Cláudia F. Falluh Baluino Ferreira. São Paulo: UNESP, 2010.

OLIVEIRA, B. S. de. Ituiutaba (MG) na rede urbana tijucana: (re)configurações sócio/espaciais no período de 1950 a 2000. 2003. 205 f. Dissertação (Mestrado em Geografia) - Universidade Federal de Uberlândia, Uberlândia, 2003.

PESSÔA, V. L. S. Ação do Estado e as transformações agrárias no Cerrado das Zonas de Paracatu e Alto Paranaíba-MG. 1988. 239 f. Tese (Doutorado em Geografia) - Universidade Estadual Paulista "Júlio de Mesquita Filho", Rio Claro, 1988.

SAMPAIO, V. S. Modernização da agricultura e seus rebatimentos nas relações de trabalho no campo brasileiro. In: VIII Encontro Baiano de Geografia, 2011, Vitória da Conquista. Anais... Vitória da Conquista: UESB, pp. 1 - 18, 2011. Disponível em: < http:// www.uesb.br/ eventos/ebg/anais/8b.pdf $>$. Acesso em: 05 jun. 2014.

SILVA, W. FUNRURAL. Contábeis: o portal da profissão contábil, 2012. Disponível em: < http://www. contabeis.com.br/forum/topicos/12115/funrural/>. Acesso em: 13 abr. 2015.
VALVERDE, O. Geografia da pecuária no Brasil. FINISTERRA Revista Portuguesa de Geografia. v. 2, n. 4, 1967. Disponível em: < http://revistas.rcaap.pt/ finisterra/article/view/2524/2152\#>. Acesso em: 10 out. 2014.

VILELA, D.; BRESSAN, M.; CUNHA, A. S. Cadeia de lácteos no Brasil: restrições ao seu desenvolvimento. Brasília: MCT/CNPq, Juiz de Fora: Embrapa Gado de Leite, 2001. 